\title{
Mechanical, Dielectric, and Microwave-Absorption Properties of Alumina Ceramic Containing Dispersed $\mathrm{Ti}_{3} \mathrm{SiC}_{2}$
}

\author{
YI LIU, ${ }^{1,2}$ FA LUO ${ }^{1}$ JINBU SU, ${ }^{1}$ WANCHENG ZHOU, ${ }^{1}$ \\ and DONGMEI $\mathrm{ZHU}^{1}$ \\ 1.-State Key Laboratory of Solidification Processing, Northwestern Polytechnical University,
} Xi'an 710072, People's Republic of China. 2.—e-mail: yiliu1021@163.com

Dense $\mathrm{Al}_{2} \mathrm{O}_{3}$ ceramics containing dispersed $\mathrm{Ti}_{3} \mathrm{SiC}_{2}$ were fabricated by hotpressed sintering. Effects of $\mathrm{Ti}_{3} \mathrm{SiC}_{2}$ content on the mechanical, dielectric, and microwave-absorption properties of the ceramics were investigated. The bulk density, flexural strength, and dielectric constant were enhanced by increasing the $\mathrm{Ti}_{3} \mathrm{SiC}_{2}$ content. The complex permittivity increased dramatically when the $\mathrm{Ti}_{3} \mathrm{SiC}_{2}$ content was above the percolation threshold. The dielectric performance of the ceramics at high temperatures was also studied. The results revealed increases in both the real and imaginary parts with increasing temperature. Ceramic $2.2 \mathrm{~mm}$ thick containing $10 \%(w / w) \mathrm{Ti}_{3} \mathrm{SiC}_{2}$ had the optimum microwave-absorption properties. The absorption bandwidth below $-5 \mathrm{~dB}$ was in the range $8.2-12.4 \mathrm{GHz}$ with a minimum value of $-20 \mathrm{~dB}$ at $9.56 \mathrm{GHz}$. Although the reflection loss increased with the increasing temperature, the ceramic still had favorable microwave-absorption properties throughout the X-band. This study contributes to the development of the microwave absorption materials for high-temperature application.

Key words: $\mathrm{Ti}_{3} \mathrm{SiC}_{2}-\mathrm{Al}_{2} \mathrm{O}_{3}$ ceramics, dielectric properties, microwave absorption, high-temperature application

\section{INTRODUCTION}

In recent years, electromagnetic (EM) waves have been widely used in military and civilian applications, for example in broadcasting, communication, and personal digital assistants, among others. Although use of EM waves can be a convenience, problems with EM wave radiation and pollution also occur. To solve these problems, microwave absorbing materials which can be used not only at room temperature but also at high temperatures have attracted much attention. Traditional microwaveabsorbing materials consist of insulating matrixes with conducting fillers. Choosing absorbents and insulating matrixes with high-temperature stability and oxidation resistance are crucial to developing microwave-absorption materials for high-temperature application. Although microwave-absorbing materials containing iron carbonyl, ${ }^{1,2}$ carbon black, ${ }^{3,4}$ and carbon nanotubes ${ }^{5,6}$ have excellent

(Received August 21, 2014; accepted December 17, 2014; published online January 9, 2015) absorption properties at room temperature, they cannot be used at high temperatures because of their low Curie temperatures or poor oxidation resistance.

$\mathrm{Ti}_{3} \mathrm{SiC}_{2}$ is a novel, readily machinable, ternary compound with both metallic and ceramic properties, for example excellent electrical conductivity, high melting point, and high-temperature oxidation resistance. ${ }^{7-9}$ These advantages make it a promising absorbent for use at high temperature.

Alumina should be an excellent candidate as the insulating matrix. Alumina, an important electroceramic material with ultra-low dielectric loss and excellent chemical stability, has been used as an insulating matrix in the $\mathrm{GHz}$ frequency range. Chojnacki et al. studied the microwave-absorbing properties of alumina multiwall CNT ceramics. ${ }^{6}$ The results indicated the material had attractive properties for use as a robust broadband microwave absorber in the 1$40 \mathrm{GHz}$ frequency range. The EM wave-absorption performance of plasma-sprayed alumina coatings containing absorbents were investigated by Zhou et al. ${ }^{10}$ Their results revealed favorable absorption by 
the coating in the $\mathrm{X}$-band. In addition, the thermal expansion coefficient of $\mathrm{Al}_{2} \mathrm{O}_{3}\left(8.8 \times 10^{-6} \mathrm{~K}^{-1}\right)$ is close to that of $\mathrm{Ti}_{3} \mathrm{SiC}_{2}\left(9.2 \times 10^{-6} \mathrm{~K}^{-1}\right)$, so the residual stress is expected to be small. This indicates alumina could be a suitable host matrix for $\mathrm{Ti}_{3} \mathrm{SiC}_{2}$. However, the dielectric and microwave absorption properties of these ceramics have rarely been reported.

In this study, $\mathrm{Ti}_{3} \mathrm{SiC}_{2}$ dispersed in alumina ceramics were fabricated by hot-pressed sintering. Effects of $\mathrm{Ti}_{3} \mathrm{SiC}_{2}$ content on the mechanical, dielectric, and microwave absorption properties were investigated. The dielectric and microwaveabsorption properties of the ceramics at high temperature were also studied.

\section{EXPERIMENTAL}

\section{Preparation of $\mathrm{Ti}_{3} \mathrm{SiC}_{2} / \mathrm{Al}_{2} \mathrm{O}_{3}$ Composites}

$\mathrm{Ti}_{3} \mathrm{SiC}_{2}$ powder was synthesized by a solid reaction method reported elsewhere. ${ }^{11}$ The as-prepared $\mathrm{Ti}_{3-}$ $\mathrm{SiC}_{2}$ powder and $\alpha-\mathrm{Al}_{2} \mathrm{O}_{3}\left(d_{50}=2 \mu \mathrm{m}\right.$, purchased from Ultrafine Powders, Zhejiang Province) were wet mixed with alcohol as medium, the $\mathrm{Ti}_{3} \mathrm{SiC}_{2}$ content was $0,5,10,15$, or $20 \%(w / w)$. After the slurries had been dried and passed through a 100-mesh sieve, the powder mixtures were sintered at $1450^{\circ} \mathrm{C}$ for $2 \mathrm{~h}$ under vacuum $(20 \mathrm{MPa})$. The chamber was evacuated to $<6 \mathrm{~Pa}$ before starting the sintering process.

\section{Characterization}

The phase compositions of the samples were identified by XRD with $\mathrm{Cu} \mathrm{K} \alpha$ radiation (X-Pert diffractometer; Philips, the Netherlands). The morphology was characterized by scanning electron microscopy (Jeol, Tokyo, Japan; model JSM-6360). The bulk densities of the sintered ceramics were measured by the Archimedes method. Flexural strength was tested by use of the three-point bending method with samples of size $3 \mathrm{~mm} \times 4 \mathrm{~mm} \times 40 \mathrm{~mm}$. Complex permittivity were measured by use of a vector network analyzer (Agilent Technologies E8362B; $10 \mathrm{MHz}-20 \mathrm{GHz}$ ), in the frequency range $8.2-12.4 \mathrm{GHz}$, with use of a heating device. The composite ceramics were cut into rectangular blocks of size $22.86 \mathrm{~mm}$ (length) $\times 10.16 \mathrm{~mm}$ (width) $\times 2.58 \mathrm{~mm}$ (thickness). The reflection loss (RL) of the samples was calculated by use of transmission line theory on the basis of measured dielectric constants (Eqs. 1-3). ${ }^{12-14}$ :

$$
\begin{gathered}
R L(d B)=20 \log \left|\left(Z_{\text {in }}-Z_{0}\right) /\left(Z_{\text {in }}+Z_{0}\right)\right| \\
Z_{0}=\sqrt{\mu_{0} / \varepsilon_{0}} \\
Z_{\text {in }}=Z_{0} \sqrt{\mu_{r / \varepsilon_{r}}} \tanh \left[j \frac{2 \pi}{c} \sqrt{\mu_{r} \varepsilon_{r}} f d\right],
\end{gathered}
$$

where $Z_{\text {in }}$ and $Z_{0}$ are the input impedances of absorber and free space, respectively, $\varepsilon_{r}$ and $\mu_{r}$ are the relative complex permittivity and the permeability of the absorber $\left(\mu_{r}=1\right.$ for nonmagnetic $\mathrm{Ti}_{3-}$ $\mathrm{SiC}_{2}$ ), $f$ is the $\mathrm{EM}$ wave frequency, $d$ is the thickness of the absorber, and $c$ is the velocity of light.

\section{RESULTS AND DISCUSSION}

\section{Phase Analysis}

Figure 1 shows the x-ray diffraction (XRD) patterns of the mixed powders and the ceramics sintered at $1450^{\circ} \mathrm{C}$.

It is apparent that $\mathrm{Al}_{2} \mathrm{O}_{3}$ and $\mathrm{Ti}_{3} \mathrm{SiC}_{2}$ are the two main phases in the mixed powders. Diffraction peaks of $\mathrm{TiC}$ are detected and the intensities increase with increasing $\mathrm{Ti}_{3} \mathrm{SiC}_{2}$ content of the sintered ceramics. The main reason is that a part of $\mathrm{Ti}_{3} \mathrm{SiC}_{2}$ powders are decomposed during the sintering process, as follows ${ }^{15}$ :

$$
\mathrm{Ti}_{3} \mathrm{SiC}_{2}(\mathrm{~s}) \rightarrow \mathrm{TiC}_{x}(\mathrm{~s})+\mathrm{Si}(\mathrm{l})
$$

Diffraction peaks of $\mathrm{Si}$ are not detected in the samples because of the small amount present. First, only a small amount of the $\mathrm{Ti}_{3} \mathrm{SiC}_{2}$ powder decomposes during the sintering process, so the amount of $\mathrm{Si}$ is low. Also, $\mathrm{Si}(\mathrm{l})$ will evaporate at such a high temperature (the melting point of $\mathrm{Si}$ is $1410^{\circ} \mathrm{C}$ ). Evaporation will be promoted under the high-vacuum environment of a rotary pump. There are no
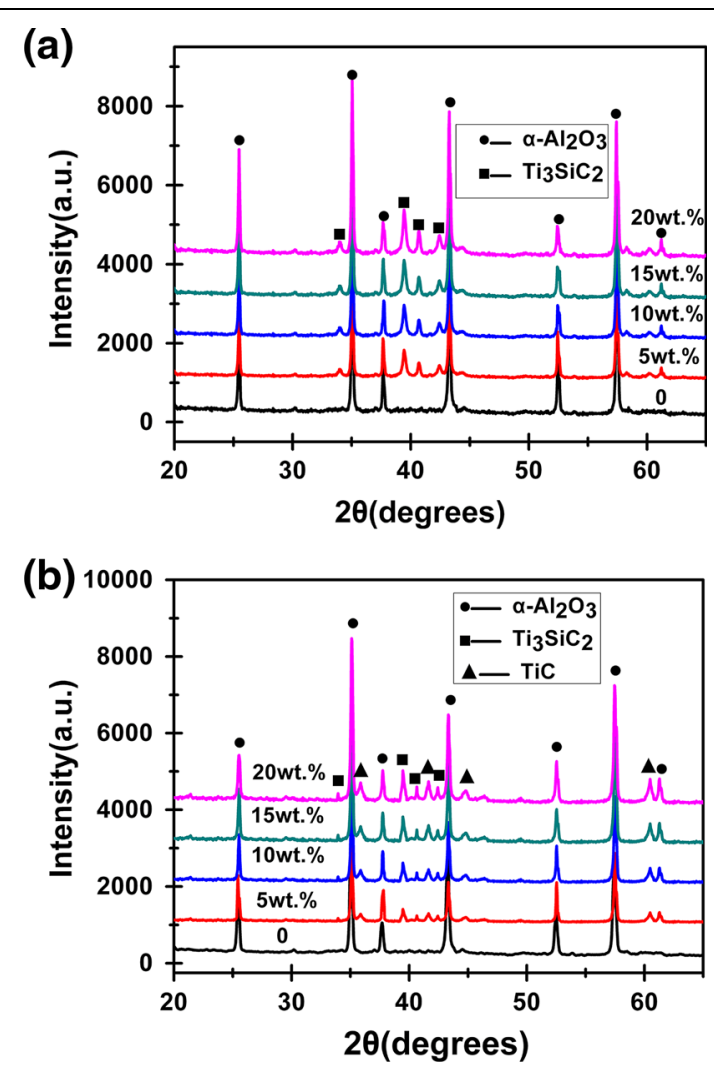

Fig. 1. XRD patterns of (a) the mixed powders and (b) the ceramics sintered at $1450^{\circ} \mathrm{C}$. 

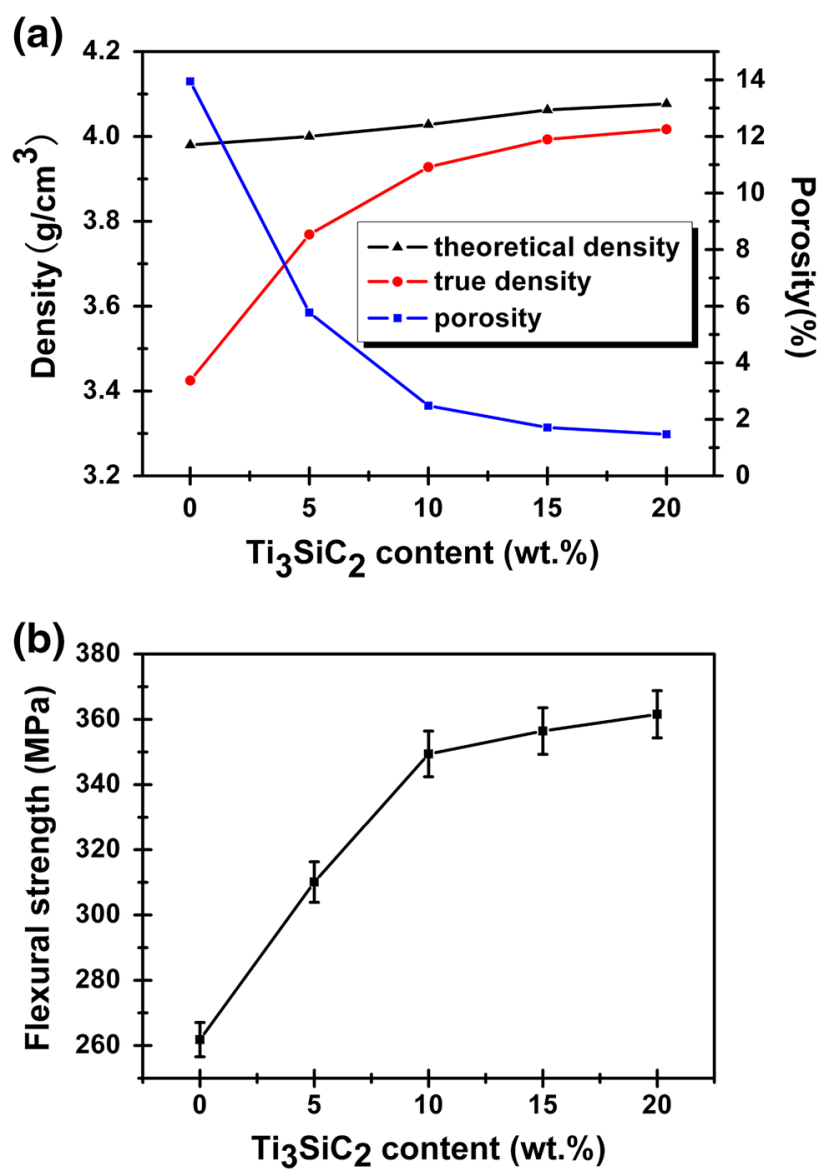

Fig. 2. Bulk density (a) and flexural strength (b) of the $\mathrm{Ti}_{3} \mathrm{SiC}_{2}-\mathrm{Al}_{2} \mathrm{O}_{3}$ ceramics.

other new phases in the ceramics, which indicates that no chemical reactions occur between the $\mathrm{Ti}_{3-}$ $\mathrm{SiC}_{2}$ and $\mathrm{Al}_{2} \mathrm{O}_{3}$ powders during sintering.

\section{Mechanical Properties}

Figure 2 shows the bulk density and flexural strength of the $\mathrm{Ti}_{3} \mathrm{SiC}_{2}-\mathrm{Al}_{2} \mathrm{O}_{3}$ ceramics.

The theoretical densities of the multiphase ceramics are calculated by use of the equation ${ }^{16}$ :

$$
\rho=\frac{\sum M_{i}}{\sum^{M_{i}} / \rho_{i}},
$$

where $\rho$ is the theoretical density of the ceramic, and $M_{i}$ and $\rho_{i}$ are the weight and density of phase $i$. The theoretical density increases with increasing $\mathrm{Ti}_{3} \mathrm{SiC}_{2}$ content, because the density of $\mathrm{Ti}_{3} \mathrm{SiC}_{2}$ $\left(4.53 \mathrm{~g} / \mathrm{cm}^{3}\right)$ is higher than that of $\mathrm{Al}_{2} \mathrm{O}_{3}(3.98 \mathrm{~g} /$ $\mathrm{cm}^{3}$ ). When the $\mathrm{Ti}_{3} \mathrm{SiC}_{2}$ content is increased from 0 to $20 \%(w / w)$, the bulk density increases from $3.425 \mathrm{~g} / \mathrm{cm}^{3}$ to $4.017 \mathrm{~g} / \mathrm{cm}^{3}$ and the porosity decreases from $13.9 \%$ to $1.5 \%$. As discussed above, decomposition of $\mathrm{Ti}_{3} \mathrm{SiC}_{2}$ results in the presence of $\mathrm{Si}(\mathrm{l})$ in the ceramics; this acts as a sintering aid and promotes densification.
The flexural strengths of the ceramics are illustrated in Fig. 2b. It is apparent that flexural strength increases from $260 \mathrm{MPa}$ to $360 \mathrm{MPa}$ as the $\mathrm{Ti}_{3} \mathrm{SiC}_{2}$ content is increased from $0 \%$ to $20 \%(\mathrm{w} / \mathrm{w})$. The results indicate that addition of $\mathrm{Ti}_{3} \mathrm{SiC}_{2}$ has a beneficial effect on the flexural strength of the ceramics. There are three reasons for this. First, the bulk density increases with increasing $\mathrm{Ti}_{3} \mathrm{SiC}_{2}$ content, which contributes to improvement of flexural strength by reducing the number of pores, defects, and cracks in the ceramics. Second, the dispersed $\mathrm{Ti}_{3} \mathrm{SiC}_{2}$ powder restricts the growth of alumina grains. This helps improve the flexural strength because of the fine-grain strengthening mechanism. Third, the $\mathrm{Ti}_{3} \mathrm{SiC}_{2}$ filler effectively transfers load from the $\mathrm{Al}_{2} \mathrm{O}_{3}$ matrix to $\mathrm{Ti}_{3} \mathrm{SiC}_{2}$ particles, because of $\mathrm{Al}_{2} \mathrm{O}_{3} / \mathrm{Ti}_{3} \mathrm{SiC}_{2}$ interfacial bonding, i.e. the $\mathrm{Ti}_{3} \mathrm{SiC}_{2}$ acts as a reinforcement phase which also contributes to enhancement of flexural strength.

\section{Microstructure}

Figure 3 shows SEM images of the fracture surfaces of ceramics with different $\mathrm{Ti}_{3} \mathrm{SiC}_{2}$ content. It is apparent that the number of pores in the ceramics decrease with increasing $\mathrm{Ti}_{3} \mathrm{SiC}_{2}$ content. Solid solutions are also observed in the sample with increasing $\mathrm{Ti}_{3} \mathrm{SiC}_{2}$ content, because of the appearance of $\mathrm{Si}(\mathrm{l})$, as shown in Fig. $3 \mathrm{~b}$ and c. Energydispersive spectroscopic (EDS) analysis shows that the columnar grains in the ceramics are $\mathrm{Ti}_{3} \mathrm{SiC}_{2}$ powder, which are not only uniformly distributed in the alumina matrix but also easily distinguished. It is apparent from Fig. $3 \mathrm{a}-\mathrm{c}$ that the grain size of $\mathrm{Al}_{2} \mathrm{O}_{3}$ of the composite ceramics is smaller than that of the pure alumina ceramic, which indicates that the presence of $\mathrm{Ti}_{3} \mathrm{SiC}_{2}$ hinders growth of alumina grains during the sintering process. The results are in accordance with the above discussion.

\section{Dielectric Properties}

\section{Effect of $\mathrm{Ti}_{3} \mathrm{SiC}_{2}$ Content on Dielectric Properties}

Complex permittivity $\left(\varepsilon=\varepsilon^{\prime}-j \varepsilon^{\prime \prime}\right)$ is a value characterizing the dielectric properties of materials. The dielectric performance of ceramics with different $\mathrm{Ti}_{3} \mathrm{SiC}_{2}$ content in the $8.2-12.4 \mathrm{GHz}$ frequency range is shown in Fig. 4. It is apparent that both the real and imaginary parts are enhanced with increasing $\mathrm{Ti}_{3} \mathrm{SiC}_{2}$ content, and that the complex permittivity surges substantially as the $\mathrm{Ti}_{3} \mathrm{SiC}_{2}$ content is increased from 15 to $20 \%(w / w)$. The real part indicates the storage capacity of the material, which is mainly attributed to polarization (relaxation and interfacial polarization) of the free charges which accumulate at the interfaces between the insulating matrix and conducting filler. In this materials, more interfaces will be formed between $\mathrm{Al}_{2} \mathrm{O}_{3}$ and $\mathrm{Ti}_{3} \mathrm{SiC}_{2}$ with increasing $\mathrm{Ti}_{3} \mathrm{SiC}_{2}$ content. So the polarization (especially interfacial polarization) ability of the 

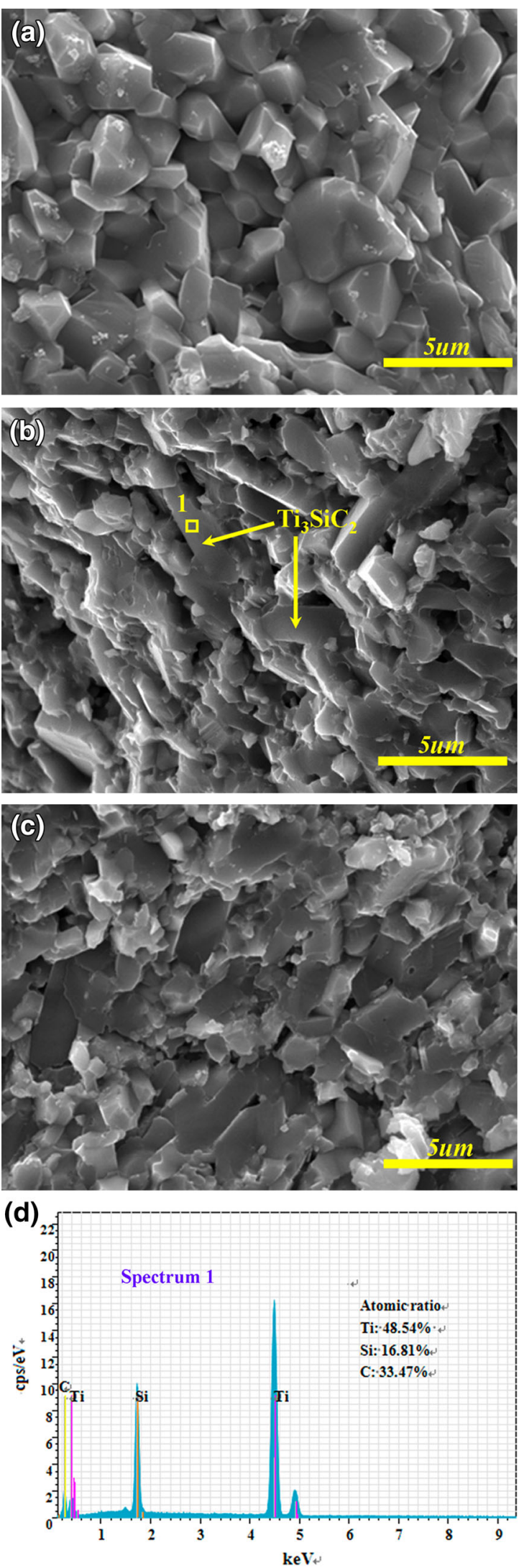

Fig. 3. SEM images of the fracture surfaces of ceramics with different $\mathrm{Ti}_{3} \mathrm{SiC}_{2}$ contents: (a) 0, (b) 10 , and (c) $20 \%(w / w)$.
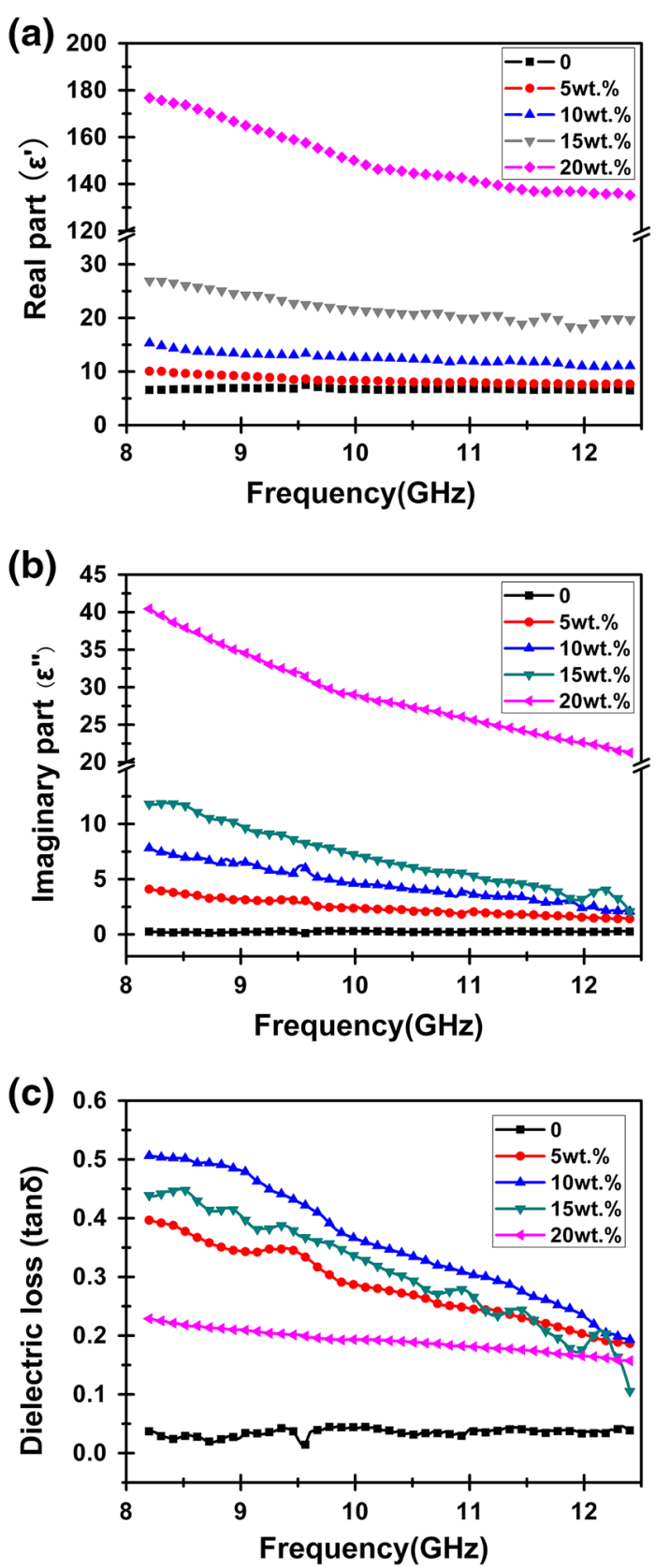

Fig. 4. Dielectric performance of ceramics with different $\mathrm{Ti}_{3} \mathrm{SiC}_{2}$ content in the $8.2-12.4 \mathrm{GHz}$ frequency range: (a) real part, (b) imaginary part, and (c) dielectric loss.

ceramic is reinforced under an external alternating electronic field, which contributes to the increase of the real part.

The imaginary part $\left(\varepsilon^{\prime \prime}\right)$, which represents the lossy capacity, is also related to the $\mathrm{Ti}_{3} \mathrm{SiC}_{2}$ content. $\varepsilon^{\prime \prime}$ is mainly dominated by the electric conductivity of the materials which, according to free-electron theory, can be expressed $\mathrm{as}^{11}$ :

$$
\varepsilon^{\prime \prime}=\sigma / \omega \varepsilon_{0}=\sigma / 2 \pi f \varepsilon_{0},
$$


where $\sigma$ is the electrical conductivity, $\varepsilon_{0}$ is the free space permittivity and $f$ is the frequency. It is clear that the increase of $\varepsilon^{\prime \prime}$ with increasing $\mathrm{Ti}_{3} \mathrm{SiC}_{2}$ content is attributed to the increase of electrical conductivity. The conductivity of the ceramic consisting of insulating matrix $\left(\mathrm{Al}_{2} \mathrm{O}_{3}\right)$ and conducting filler $\left(\mathrm{Ti}_{3} \mathrm{SiC}_{2}\right)$ is dominated by the interparticle distance of the filler, as expressed by ${ }^{17}$ :

$$
\delta=D\left[(\pi / 6 \varphi)^{1 / 3}-1\right],
$$

where $\delta$ is the average interparticle distance, $D$ is the particle diameter, and $\varphi$ is the volume fraction of the fillers. The interparticle distance of the fillers decreases with increasing $\mathrm{Ti}_{3} \mathrm{SiC}_{2}$ content, as shown in Fig. 3. So free electrons can hop between filler particles which form a conducting network; this helps improve the conductivity and the imaginary part. When the $\mathrm{Ti}_{3} \mathrm{SiC}_{2}$ content is increased from 15 to $20 \%(w / w)$, the surge of the complex permittivity is attributed to the percolation effect. The electric conductivity will increase abruptly as the $\mathrm{Ti}_{3} \mathrm{SiC}_{2}$ content is close to the percolation threshold, which results in the surge of the complex permittivity.

The dielectric loss of the ceramic is analyzed by use of the equation $\tan \delta=\varepsilon^{\prime \prime} / \varepsilon^{\prime}$. The value for the pure $\mathrm{Al}_{2} \mathrm{O}_{3}$ ceramic is close to 0 , implying $\mathrm{Al}_{2} \mathrm{O}_{3}$ ceramic is a low lossy material for EM waves. The dielectric loss first increases then decreases as the $\mathrm{Ti}_{3} \mathrm{SiC}_{2}$ content rises from 0 to $20 \%(w / w)$. The value is highest for ceramic doped with $10 \%(w / w) \mathrm{Ti}_{3} \mathrm{SiC}_{2}$. The impedances of microwave-absorbing materials are required to match the impedance free space, so the EM wave can enter and subsequently be attenuated inside the material.

\section{Effects of Temperature on Dielectric Properties}

To understand the effects of temperature on dielectric properties, the complex permittivity of the ceramics in the $\mathrm{X}$-band was tested at $25-400^{\circ} \mathrm{C}$. The real and imaginary parts of the complex permittivity of the ceramic containing $10 \%(w / w) \mathrm{Ti}_{3} \mathrm{SiC}_{2}$ at five different temperatures are shown in Fig. 5. The dielectric constants of ceramics with other $\mathrm{Ti}_{3} \mathrm{SiC}_{2}$ content are not shown here because the complex permittivity has a similar trend with increasing temperature. It is observed that both the real and imaginary part increase with the increasing temperature. The real part increases from 15.29 to 20.36 and the imaginary part increases from 7.83 to 9.53 as the temperature increases from 25 to $400^{\circ} \mathrm{C}$. The temperature dependence of the real part can be illustrated by the Debye theory ${ }^{18,19}$ :

$$
\varepsilon^{\prime}=\varepsilon_{\infty}+\left(\varepsilon_{s}-\varepsilon_{\infty}\right) /\left[1+\omega^{2} \tau(T)^{2}\right]
$$

where $\omega$ is the angular frequency, $\varepsilon_{s}$ is the static (zero frequency), $\varepsilon_{\infty}$ is the relative dielectric
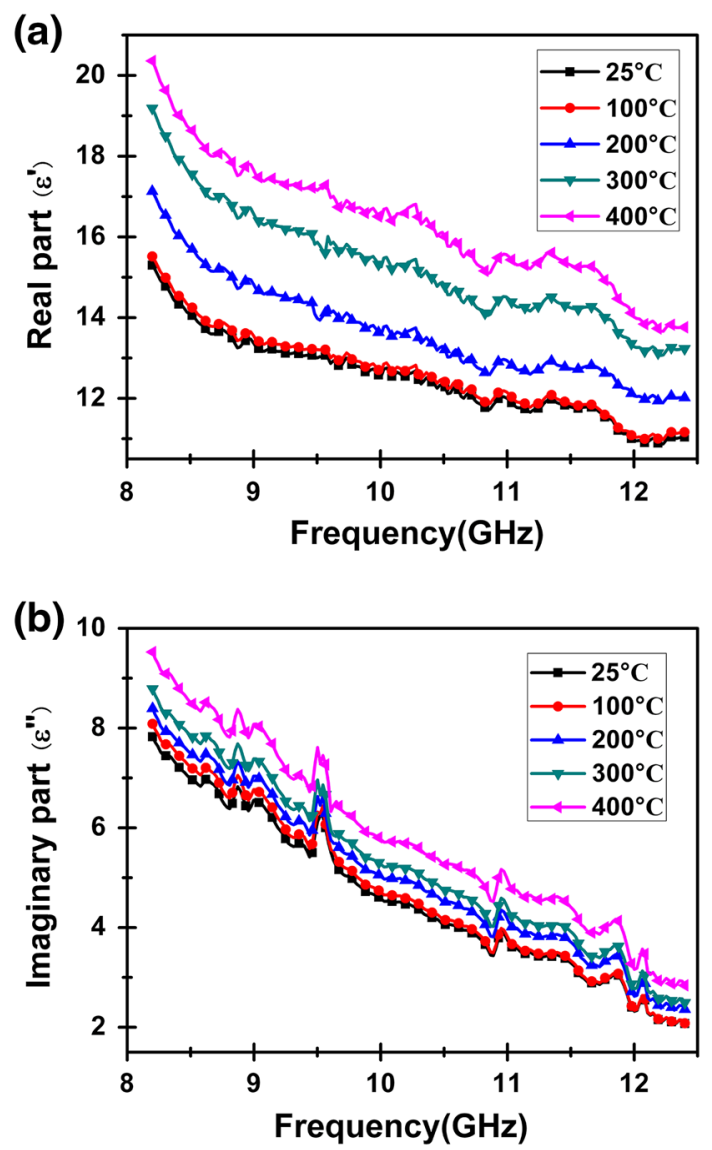

Fig. 5. Complex permittivity of the ceramic containing $10 \%(w / w)$ $\mathrm{Ti}_{3} \mathrm{SiC}_{2}$ in the temperature range ${ }^{25}-400^{\circ} \mathrm{C}$ : (a) real part, (b) imaginary part.

permittivity at the frequency limit, and $\tau(T)$ is the relaxation time. As shown in Eqs. 6 and 8, the real and imaginary parts of the complex permittivity are determined by the relaxation time $\tau(T)$ and the electric conductivity $\sigma$, respectively, which depend on the temperature. The relaxation time is given $\mathrm{by}^{20}$ :

$$
\tau(T)=\tau_{0} \exp \left(E_{0 / R T}\right),
$$

where $\tau_{O}$ is the prefactor, $R$ is the Boltzmann constant, and $E_{a}$ is the activation energy. The conductivity is expressed by use of the Arrhenius formula ${ }^{21}$ :

$$
\sigma(T)=\sigma_{0} \exp \left(-E_{g} / 2 R T\right),
$$

where $\sigma_{0}$ is a prefactor for migrating behavior and $E_{g}$ is the band gap. From Eqs. 9 and 10 it is apparent that relaxation time will decrease and the electric conductivity will increase with increasing temperature. Therefore, both the real and imaginary parts of the complex permittivity increase with increasing temperature. 


\section{Microwave Absorption Property}

$\mathrm{RL}$ was calculated to further investigate the microwave absorption properties of the ceramic. This is defined $\mathrm{as}^{22}$ :

$$
R L=10 \log P_{R / P_{I}}(d B),
$$

where $P_{I}$ and $P_{R}$ are, respectively, the incident power and reflected power of the microwaves. For example, when $\mathrm{RL}$ is $-5 \mathrm{~dB}, 70 \%$ of the microwaves are absorbed and $30 \%$ are reflected.

\section{Microwave-Absorption Properties of Ceramics with Different $\mathrm{Ti}_{3} \mathrm{SiC}_{2}$ Contents}

The RL calculated for $2.2 \mathrm{~mm}$ thick $\mathrm{Ti}_{3} \mathrm{SiC}_{2}-$ $\mathrm{Al}_{2} \mathrm{O}_{3}$ ceramics with different $\mathrm{Ti}_{3} \mathrm{SiC}_{2}$ contents are shown in Fig. 6. The RL value first decreases then increases when the $\mathrm{Ti}_{3} \mathrm{SiC}_{2}$ content increases from 0 to $20 \%(w / w)$. The ceramic doped with $10 \%(w / w)$ $\mathrm{Ti}_{3} \mathrm{SiC}_{2}$ has the optimum microwave-absorbing performance. RL values $<-5 \mathrm{~dB}$ are obtained throughout the frequency range, with a minimum value of $-20 \mathrm{~dB}$ at $9.56 \mathrm{GHz}$. As discussed above, the dielectric loss value is highest for the ceramic doped with $10 \%(w / w) \mathrm{Ti}_{3} \mathrm{SiC}_{2}$, which demonstrates it can turn more EM wave energy into heat. Although high $\varepsilon^{\prime \prime}$ is necessary for good microwaveabsorbing properties, permittivity which is too high is detrimental to impendence matching, which leads to strong reflection of the incident EM wave and poor absorption.

The normalized input impedances $\left(Z=Z_{\text {in }} / Z_{0}\right)$ of $\mathrm{Ti}_{3} \mathrm{SiC}_{2}-\mathrm{Al}_{2} \mathrm{O}_{3}$ ceramics $2.2 \mathrm{~mm}$ thick are shown in Fig. 7. Both the real and imaginary parts of the input impedance are first enhanced then decrease as the $\mathrm{Ti}_{3} \mathrm{SiC}_{2}$ content increases from 0 to $20 \%(\mathrm{w} /$ $w)$. The impedance of the ceramic doped with $10 \%$ $(w / w) \mathrm{Ti}_{3} \mathrm{SiC}_{2}$ is closest to the optimum normalized input impedance value, which is $Z^{\prime}=1$ and $Z^{\prime \prime}=0$. Ceramics with low or high $\mathrm{Ti}_{3} \mathrm{SiC}_{2}$ content deviate from the matching condition, which results in poor absorption properties. When the amount of $\mathrm{Ti}_{3} \mathrm{SiC}_{2}$

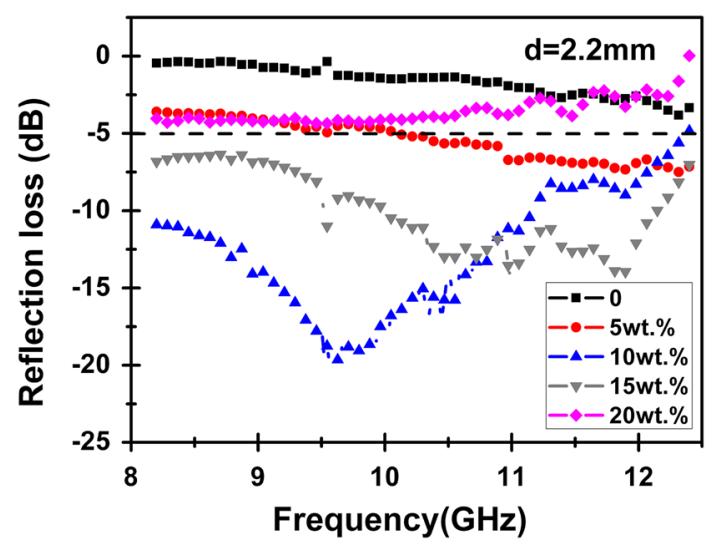

Fig. 6. $\mathrm{RL}$ of $2.2 \mathrm{~mm}$ thick $\mathrm{Ti}_{3} \mathrm{SiC}_{2}-\mathrm{Al}_{2} \mathrm{O}_{3}$ ceramics. added is low the ceramic cannot convert EM wave energy completely to heat whereas a high $\mathrm{Ti}_{3} \mathrm{SiC}_{2}$ content leads to strong reflection of the incident wave. Ceramic doped with $10 \%(w / w) \mathrm{Ti}_{3} \mathrm{SiC}_{2}$ fits the matching condition well, which results in the most favorable microwave absorption.

The effect of thickness on microwave absorption was investigated; results for ceramic of different thickness containing $10 \%(w / w) \mathrm{Ti}_{3} \mathrm{SiC}_{2}$ are shown in Fig. 8. It is apparent that the minimum RL peak
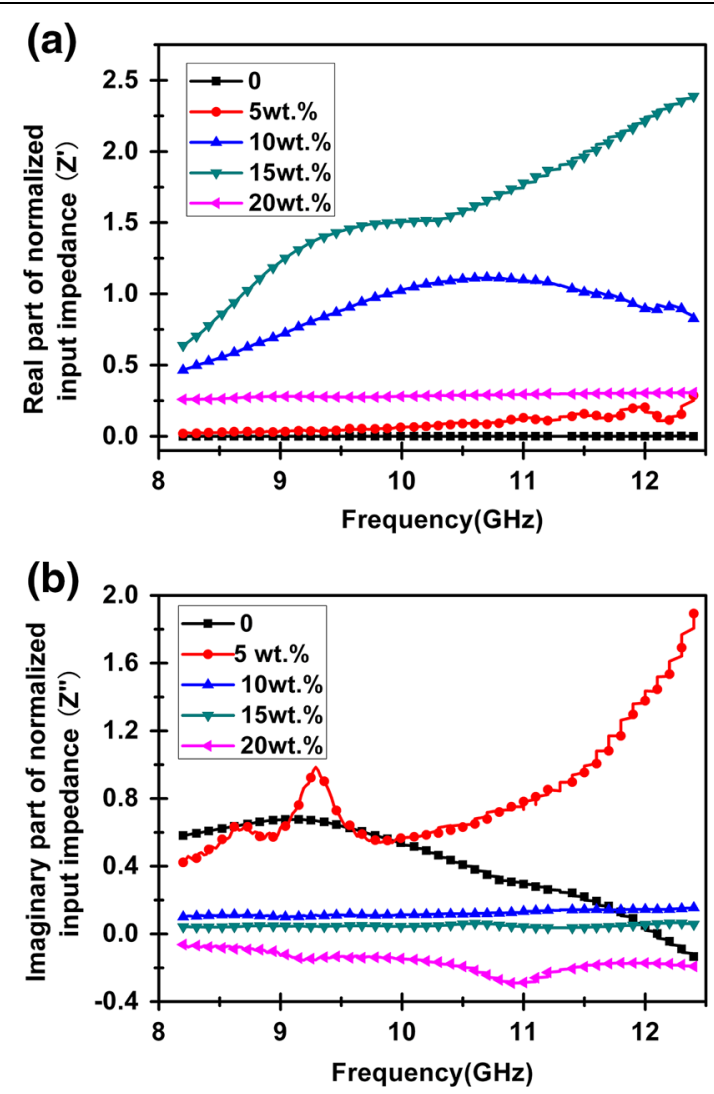

Fig. 7. Normalized input impedances of $2.2 \mathrm{~mm}$ thick $\mathrm{Ti}_{3} \mathrm{SiC}_{2}-\mathrm{Al}_{2} \mathrm{O}_{3}$ ceramics: (a) real part, (b) imaginary part.

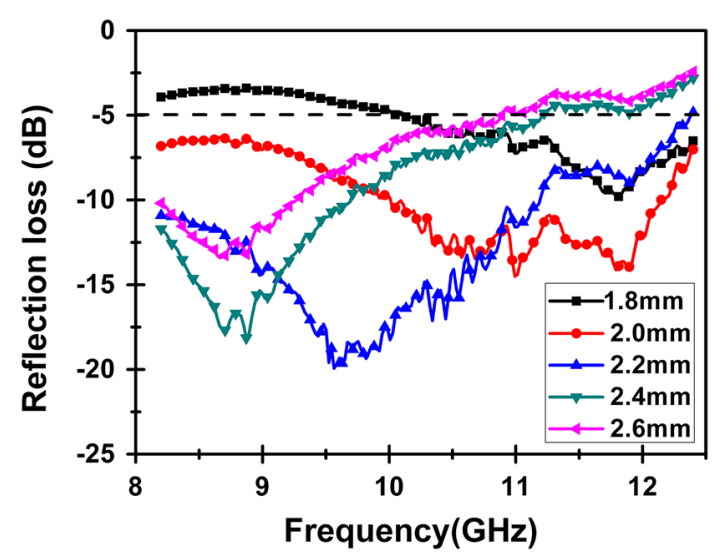

Fig. 8. $\mathrm{RL}$ of ceramic of different thickness containing $10 \%(w / w)$ $\mathrm{Ti}_{3} \mathrm{SiC}_{2}$. 


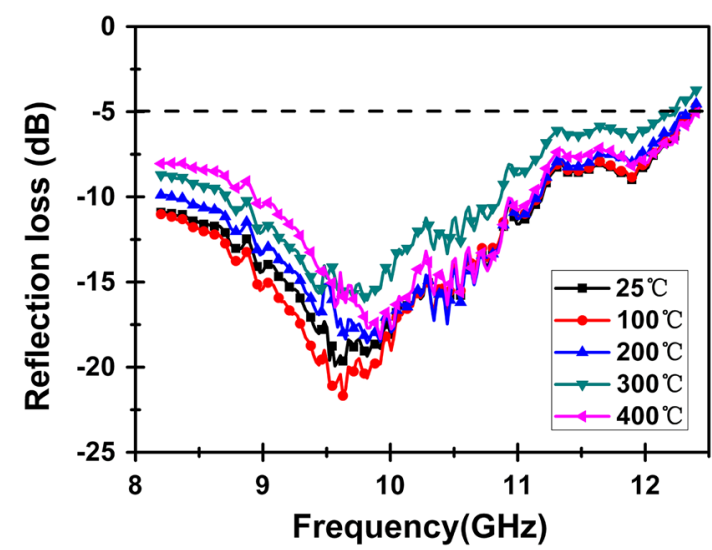

Fig. 9. $\mathrm{RL}$ of ceramic containing $10 \%(w / w) \mathrm{Ti}_{3} \mathrm{SiC}_{2}$ at different temperatures.

shifts toward the lower-frequency range with the increasing thickness, which is in accordance with the relationship between the matching frequency and thickness, expressed $\operatorname{as}^{23}$ :

$$
f_{m}=c / 4 d_{m} \bullet 1 / \sqrt{\varepsilon^{\prime} \mu^{\prime}} \bullet\left(1+\tan ^{2} \delta / 8\right)^{-1},
$$

where $f_{\mathrm{m}}$ and $d_{\mathrm{m}}$ are the matching frequency and thickness, respectively, $\tan \delta$ is the dielectric loss, and $c$ is the velocity of light. It is clear that the matching frequency decreases with increasing thickness because $\sqrt{\varepsilon^{\prime} \mu^{\prime}}$ is constant.

\section{High Temperature Microwave-Absorption Properties}

The RL of ceramic $2.2 \mathrm{~mm}$ thick containing $10 \%$ $(w / w) \mathrm{Ti}_{3} \mathrm{SiC}_{2}$ in the temperature range $25-400^{\circ} \mathrm{C}$ is presented in Fig. 9. It is apparent that RL increases slightly with the increasing temperature but the ceramic still has favorable microwave-absorption performance throughout the $\mathrm{X}$-band. These results indicate that the $\mathrm{Ti}_{3} \mathrm{SiC}_{2}-\mathrm{Al}_{2} \mathrm{O}_{3}$ ceramic is a potential microwave absorption material for high-temperature application.

\section{CONCLUSIONS}

$\mathrm{Ti}_{3} \mathrm{SiC}_{2}$ powder was added to $\mathrm{Al}_{2} \mathrm{O}_{3}$ ceramic to fabricate a microwave-absorption material for hightemperature application. The mechanical, dielectric, and microwave absorption properties of the ceramics are affected by $\mathrm{Ti}_{3} \mathrm{SiC}_{2}$ content. The composite ceramic containing $10 \%(w / w) \mathrm{Ti}_{3} \mathrm{SiC}_{2}$ has the optimum microwave absorption properties. An absorption peak at $9.56 \mathrm{GHz}$ with a minimum RL value of $-20 \mathrm{~dB}$ is obtained for a sample $2.2 \mathrm{~mm}$ thick. An absorption bandwidth below $-5 \mathrm{~dB}$ is obtained throughout the frequency range 8.2$12.4 \mathrm{GHz}$. As the temperature is increased from 25 to $400^{\circ} \mathrm{C}$, the ceramic still has favorable microwaveabsorption properties throughout the $\mathrm{X}$-band. These results indicate that the $\mathrm{Ti}_{3} \mathrm{SiC}_{2}-\mathrm{Al}_{2} \mathrm{O}_{3}$ ceramic is a potential microwave absorption material for hightemperature application.

\section{ACKNOWLEDGEMENT}

This work was supported by National Natural Science Foundation of China, no. 51072165. This work was financially supported by the fund of the States Key Laboratory of the Solidification Processing in NWPU, no. KP201307.

\section{REFERENCES}

1. Y.B. Feng, T. Qiu, and C.Y. Shen, J. Magn. Magn. Mater. 318, 12 (2007).

2. B.C. Wang, J.Q. Wei, L. Qiao, T. Wang, and F.S. Li, J. Magn. Magn. Mater. 324, 763 (2012).

3. X.X. Liu, Z.Y. Zhang, and Y.P. Wu, Comp Part B 42, 328 (2011).

4. Y.W. Dai, M.Q. Sun, C.G. Liu, and Z.Q. Li, Cem. Concr. Compos. 32, 510 (2010).

5. D.A. Makeiff and T. Huber, Synth. Met. 156, 500 (2006).

6. E. Chojnacki, Q. Huang, A.K. Mukherjee, T.B. Holland, M. Tigner, and K. Cherian, Nucl. Instrum. Methods Phys. Res. Sect. A 659, 52 (2011).

7. M.W. Barsoum and T. El-Raghy, J. Am. Ceram. Soc. 79, 1954 (1996).

8. Z.M. Sun, S.L. Yang, and H. Hashimoto, Ceram. Int. 30, 1875 (2004).

9. B.Y. Liang, S.Z. Jin, and M.Z. Wang, J. Alloys Compd. 460, $442(2008)$.

10. L. Zhou, W.C. Zhou, J.B. Su, F. Luo, D.M. Zhu, and Y.L. Dong, Appl. Surf. Sci. 258, 2694 (2012).

11. Y. Liu, F. Luo, W.C. Zhou, and D.M. Zhu, J. Alloys Compd. 576,45 (2013)

12. B. Mušič, M. Drofenik, P. Venturini, and A. Žnidaršič, Ceram. Int. 38, 2696 (2012).

13. L.D. Liu, Y.P. Duan, L.X. Ma, S.H. Liu, and Z. Yu, Appl. Surf. Sci. 257, 844 (2010).

14. Y.K. Liu, Y.J. Feng, X.W. Wu, and X.G. Han, J. Alloys Compd. 472, 443 (2009).

15. C. Racult, F. Langlais, and R. Naslain, J. Mater. Sci. 29, 3388 (1994).

16. S.H. Wu, X.S. Wei, X.Y. Wang, H.X. Yang, and S.Q. Gao, J. Mater. Sci. Technol. 26, 474 (2010).

17. Z.B. Huang, W.C. Zhou, X.F. Tang, and J.K. Zhu, J. Alloys Compd. 509, 1922 (2011).

18. H.T. Guan, Y.D. Wang, G. Chen, and J. Zhu, Powder Technol. 224, 357 (2012).

19. J. Yuan, W.L. Song, X.Y. Fang, X.L. Shi, Z.L. Hou, and M.S Cao, Solid State Commun. 154, 66 (2013).

20. H.T. Guan, G. Chen, J. Zhu, and Y.D. Wang, J. Alloys Compd. 507, 129 (2010).

21. S.A. Ansari, A. Nisar, B. Fatma, W. Khan, M. Chaman, A. Azam, and A.H. Naqvi, Mater. Res. Bull. 47, 4166 (2012).

22. X. Hao, X.W. Yin, L.T. Zhang, and L.F. Cheng, J. Mater. Sci. Technol. 29, 253 (2013).

23. J. Sun, H.L. Xu, Y. Shen, H. Bi, W.F. Liang, and R.B. Yang, J. Alloys Compd. 548, 20 (2013). 